\title{
NOTES
}

\section{The Effect of Polymer Rigidity on Photoisomerization of 4-Dimethylamino-4'-nitroazobenzene}

\author{
Takuya NAITo, ${ }^{*}$ Kazuyuki HoriE, and Itaru Mita \\ Department of Reaction Chemistry, Faculty of Engineering, The University of Tokyo, \\ 7-3-1, Hongo, Bunkyo-ku, Tokyo 113, Japan
}

(Received October 30, 1990)

\begin{abstract}
KEY WORDS Polyimide / Polyetherimide / Polycarbonate / Poly(methyl methacrylate) / trans-to-cis Photoisomerization / 4-Dimethylamino-4'nitroazobenzene (DANAB) / Free-Volume /
\end{abstract}

The main characteristics of reactions in polymer films are non-first-order progress of reactions, which are expected to be unimolecular in solution, because of the heterogeneous distribution of the reaction sites due to the restriction of chain mobility in solid state. ${ }^{1,2}$ The photoisomerization of azobenzene and its derivatives in polymer films was studied by many investigators for recent years. ${ }^{3-11}$ In our previous papers, trans-to-cis photoisomerizations of azobenzene (AZB), ${ }^{12,13} 1,1^{\prime}$-azonaphthalene $(\mathrm{AZN}),{ }^{12,14}$ 9,9'-azophenanthrene $(\mathrm{AZP})^{15}$ and stilbene (STL) ${ }^{15}$ in polycarbonate (PC) films were studied over the wide temperature range $(4-423 \mathrm{~K})$, and effects of free-volume distribution, bulkiness of mobile group and sweeping envelope depending on isomerization mechanism ${ }^{15}$ on the solid state reactions were discussed.

In this paper, the study is extended to transto-cis photoisomerization in aromatic polymides and other linear polymer solids. A 4dimethylamino-4'-nitroazobenzene (DANAB) was used as a photoreactive probe, since the strong absorption of polyimides overlaps the usual absorption bands ( $\pi, \pi^{*}$-transition) of non-substituted azo-compounds. The present study aims at discussing the difference in rigidity of various linear matrix polymers based on the reactivity of the azo-compound.

\section{EXPERIMENTAL}

4-Dimethylamino-4'-nitroazobenzene (DANAB) was obtained from Tokyo Kasei Kogyo Co., Ltd., polycarbonate (PC) from Teijin Co. $\left(M_{n}=6.6 \times 10^{4}, M_{w}=1.3 \times 10^{5}, M_{w} / M_{n}=1.94\right.$, $T_{\mathrm{g}}=152^{\circ} \mathrm{C}$ ), polyetherimide (PEI) from General Electrics Co. $\left(M_{n}=3.4 \times 10^{4}, M_{w}=1.0 \times\right.$ $\left.10^{5}, M_{w} / M_{n}=2.95, T_{\mathrm{g}}=231^{\circ} \mathrm{C}\right)$ and PMMA from Mitsubishi Rayon $\left(M_{n}=2.1 \times 10^{5}, T_{\mathrm{g}}=\right.$ $\left.110^{\circ} \mathrm{C}\right)$. Polyimide (PI(BPDA/PDA) $)\left(M_{w}=\right.$ $1.7 \times 10^{5}, \quad T_{\mathrm{g}}=282^{\circ} \mathrm{C}$ ) was prepared from $3,3^{\prime}, 4,4^{\prime}$-biphenyltetracarboxylic dianhydride (BPDA) and $p$-phenylenediamine (PDA). ${ }^{16}$ The chemical structures of these polymers are given below.

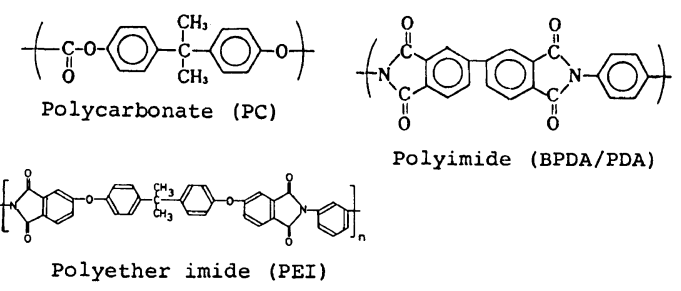

The films of polycarbonate, PMMA or polyetherimide containing molecularly dispersed DANAB (10-15 $\mu \mathrm{m}$ thickness) were prepared with solvent cast method from dichloromethane solution. The polyamic acid films with DANAB were cast from $N, N$ - 
dimethylacetamide solution, and then converted to polyimide films by thermal imidization at $150^{\circ} \mathrm{C}$ for $2 \mathrm{~h}, 200^{\circ} \mathrm{C}$ for $2 \mathrm{~h}$ in a nitrogen atmosphere. The UV-VIS absorption spectra of DANAB in polymer films are similar in shape to those in solution. It suggests that DANAB is molecularly dispersed in polymer films and does not aggregate during thermal imidization. The concentration of DANAB are set to be $(0.4-1.7) \times 10^{-2} \mathrm{~mol}^{-1}$ in order for the absorbance of the sample to be $0.15-0.3$ at absorption maximum wavelength of DANAB.

The sample films set in an Oxford DN-704 type cryostat were irradiated with the light from $150 \mathrm{~W}$ Xenon lamp (Hamamatsu L-2195) at absorption maximum of DANAB by using a combination of an interference filter and a color filter. The change in the intensity of a part of transmitted light was monitored by a photomultiplier (Hamamatsu R-374) with a monochromator (JASCO CT-10) and recorded with an $X-T$ recorder (Riken Denshi SP-H3C). The reaction was followed at various temperatures $(77-300 \mathrm{~K})$.

\section{RESULTS AND DISCUSSION}

Typical changes in the UV-VIS spectra of DANAB in solution and in polymer film during trans-to-cis photoisomerization with the light at absorption maximum are shown in Figures $1(a, b)$, respectively. The change in concentration of $c i s-D A N A B,[\mathrm{cis}]_{t}$, was calculated from the optical density at time $t, \mathrm{OD}_{t}$, by using eq 1 .

$$
\begin{gathered}
{[\mathrm{cis}]_{t}=\frac{1-\mathrm{OD}_{t} / \mathrm{OD}_{0}}{1-\varepsilon_{c i s} / \varepsilon_{t r}}[\mathrm{tr}]_{0} ;} \\
{[\mathrm{tr}]_{t}=[\mathrm{tr}]_{0}-[\mathrm{cis}]_{t}}
\end{gathered}
$$

The $c i s$-DANAB is not stable at room temperature owing to the rapid thermal cis-to-trans isomerization. Therefore, the absorption spectrum of cis-DANAB was determined by extrapolating from the spectrum of a photoequilibrium mixture of cis and trans-forms
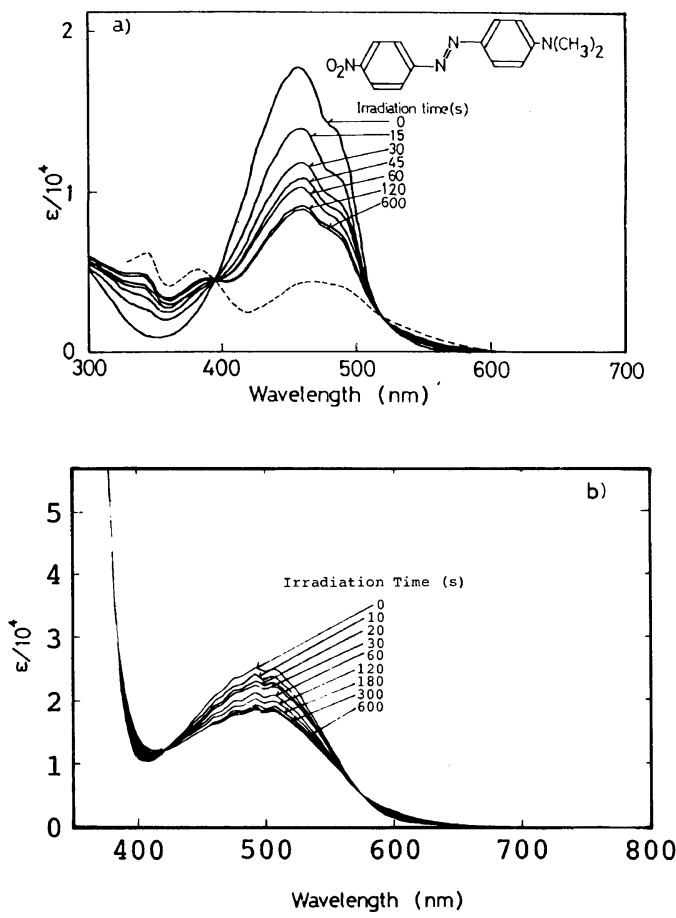

Figure 1. Changes in UV-VIS absorption spectra of 4-dimethylamino-4'-nitroazobenzene (DANAB) in methylcyclohexane solution (a, solid lines) and in polyetherimide film (b) during absorption maximum wavelength light irradiation at $230 \mathrm{~K}$. The UV-VIS absorption spectrum of cis-DANAB in methylcyclohexane (a, dashed line) was determined by extrapolation from the spectra of pure trans-form and photoequilibrium mixture under the irradiation of isosbestic wavelength light.

produced by the irradiation of pure trans-form at isosbestic wavelength $(514 \mathrm{~nm})$ at low termperature $(230 \mathrm{~K})$, with a similar manner to the case of $c i s-1,1^{\prime}$-azonaphthalene. ${ }^{14}$ The UV absorption spectrum of cis-DANAB is also shown in Figure 1 . The $\varepsilon_{c i s} / \varepsilon_{t r}$ is 0.232 at $460 \mathrm{~nm}$.

The typical semi-logarithmic time-conversion plots for trans-to-cis photoisomerization of DANAB are shown in Figure 2 for the polyetherimide films. The reaction proceeds with the first-order kinetics at the initial stage then deviates from the first-order kinetics, and substantially stops at limited conversion, $X_{\mathrm{f}}$, since the residual reaction sites have local free-volume much smaller than the volume necessary for the photoisomerization. ${ }^{12-15}$ 


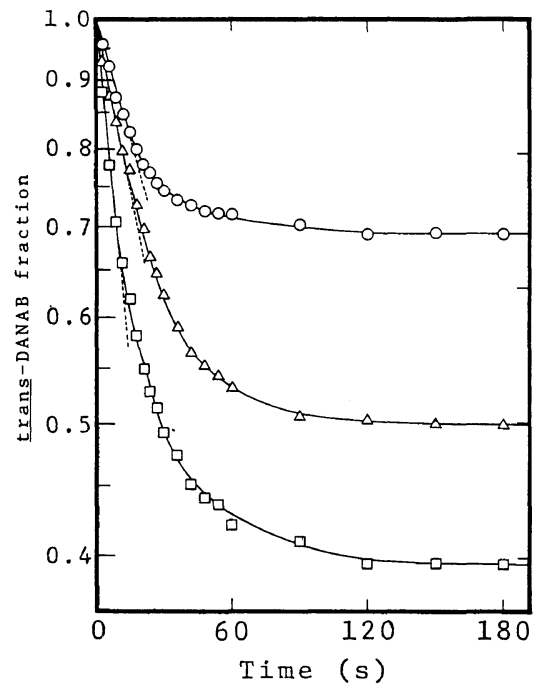

Figure 2. Typical semi-logarithmic time-conversion plots for trans-to-cis photoisomerization of 4-dimethylamino-4' nitroazobenzene (DANAB) in polyetherimide films at 80 $(\mathrm{O}), 125(\triangle)$, and $170(\square) \mathrm{K}$.

The Arrhenius plots, determined from the initial slopes of semilogarithmic plots such as Figure 2, for trans-to-cis photoisomerization of DANAB in various polymers fit in almost parallel lines (Figure 3) with apparent activation energy of about $0.2 \mathrm{kcal} \mathrm{mol}^{-1}$. This value is comparable to the case of apparent activation energy for non-substituted azobenzene at the same temperature range in various polymers. ${ }^{17}$ In our previous papers, ${ }^{12-15}$ we proposed the reaction sites in polymers are divided into two parts, i.e., in the first part, photo-probe can isomerize freely as in solution, and in the other part, mobility of photo-probe is restricted and controlled by matrices. We suppose that the increases in proportion of the restricted part in polymers at low temperature is reflected by the apparent activation energy of the photoisomerization at the initial stage in Figure 2.

The final cis-fractions for the trans-to-cis photoisomerization of DANAB in polymer films as a function of temperature are illustrated in Figure 4. The decreases in final cis-fraction with increasing temperature above $160 \mathrm{~K}$ are attributed to the thermal cis-to-trans

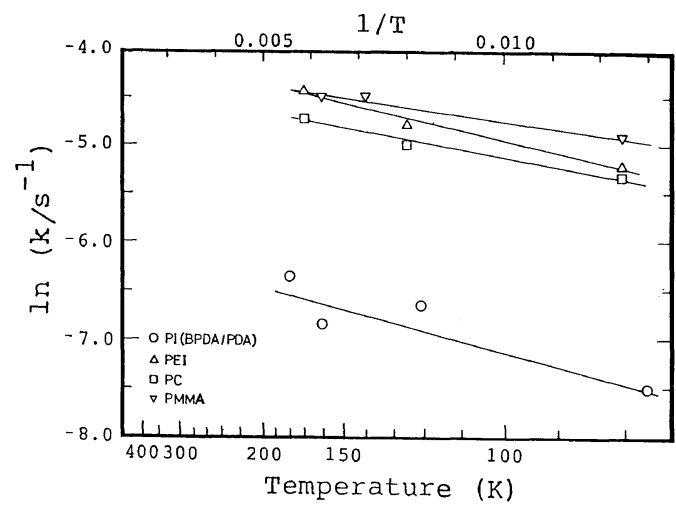

Figure 3. Arrhenius plots of the initial apparent rates for trans-to-cis photoisomerization of DANAB in various polymer films.

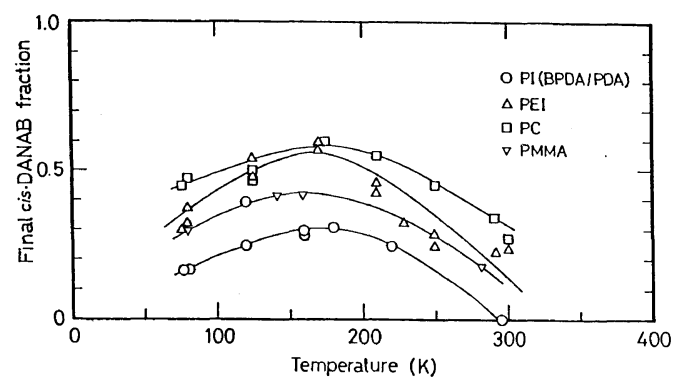

Figure 4. The final $c i s$-fractions, $X_{\mathrm{f}}$, against temperature for photoisomerization of 4-dimethylamino-4'-nitroazobenzene (DANAB) in various polymer films.

backward isomerization. Its first-order rate constant was measured to be $5.7 \times 10^{-4} \mathrm{~s}^{-1}$ in methylcyclohexane at $230 \mathrm{~K}$. The first-order rate constants for the thermal cis-to-trans isomerization of DANAB and non-substituted azobenzene in hexane at $293 \mathrm{~K}$ were reported to be $2.7 \times 10^{-3} \mathrm{~s}^{-1}$ and $2.5 \times 10^{-6} \mathrm{~s}^{-1}$, respectively. ${ }^{18}$ The final cis-fractions decrease in all polymers with decreasing temperature below $160 \mathrm{~K}$ where the cis-to-trans thermal backward reaction is negligible. The decrease is caused by the suppression of local mobilities of the matrix polymers at lower temperatures.

The values of the final cis-fractions, $X_{\mathrm{f}}$, for photoisomerization of DANAB reach $0.45-0.6$ in polycarbonate at $80-160 \mathrm{~K}$ and become a little smaller in polyetherimide, but the values 
of the final cis-fraction of DANAB in PI (BPDA/PDA) are less than half of those in polycarbonate. The very small values of $X_{\mathrm{f}}$ in PI (BPDA/PDA) compared to those in polycarbonate and polyetherimide would be attributed to the fact that both polycarbonate and polyetherimide have a bisphenol-A structure in their repeating units, which makes their main chains flexible and free-volume fluctuation large. Polycarbonate is well known to show large local relaxation process at $150-170 \mathrm{~K}$ called $\gamma$-transition. ${ }^{19-21}$ On the other hand, PI (BPDA/PDA) contains only aromatic and imide rings in its main chain, that means no flexible parts exist in its structure. The intermolecularly stacked higher-order structure of PI (BPDA/PDA) supposed as a reason of its excellent mechanical properties, ${ }^{22}$ thus, is microscopically reflected by the small $X_{\mathrm{f}}$ values in Figure 4.

The comparison of main chain aromatic polymers with vinyl type polymers is also noteworthy. The final cis-fractions in PMMA are smaller than those in polycarbonate regardless of similar density to each other (PMMA, 1.1923,24; polycarbonate, $1.20^{23,25}$ ). The fractional van der Waals volume was calculated to be 0.671 for PMMA and 0.633 for polycarbonate by using atomic increment method, ${ }^{26}$ suggesting the smaller average free-volume in PMMA than in polycarbonate. The distribution of local free-volume in PMMA with flexible methylene main chains is supposed to be narrower than that in polycarbonate with bulky aromatic chains. Since the side chains of PMMA are more mobile than its main chain, the site with large local free-volumes are possibly filled up and free-volume distribution is homogenized by the side chains, while this does not occur in polycarbonate without side chains. Therefore the fraction of sites which are large enough for isomerization to occur becomes smaller in PMMA, and it would be the reason of smaller final cis-conversions of DANAB in PMMA than in polycarbonate.
In conclusion, rigidity of polymers is microscopically reflected by the reactivity of solid-state intramolecular reactions which can be measured, even in an aromatic polyimides, by using photoisomerization of DANAB.

Acknowledgment. This work was supported in part by Grants-in-Aid for Scientific Research on Priority Area of "Macromolecular Complexes" from the Ministry of Education, Science, and Culture of Japan.

\section{REFERENCES}

1. G. Smets, Adv. Polym. Sci., 50, 17 (1983).

2. K. Horie and I. Mita, Adv. Polym. Sci., 88, 77 (1989).

3. C. S. P. Sung and H. Morawetz, Macromolecules, 5, 171 (1972).

4. C. D. Eisenbach, Makromol. Chem., 179, 2489 (1978).

5. C. S. P. Sung, L. Lamarre, and M. K. Tse, Macromolecules, 12, 666 (1979).

6. C. D. Eisenbach, Ber. Bunsen-Ges. Phys. Chem., 84, 680 (1980).

7. C. S. P. Sung, L. Lamarre, and K. H. Chung, Macromolecules, 14, 1839 (1981).

8. L. Lamarre and C. S. P. Sung, Macromolecules, 16, 1729 (1983).

9. C. S. P. Sung, I. R. Gould, and N. J. Turro, Macromolecules, 17, 1447 (1984).

10. J. G. Victor and J. M. Torkelson, Macromolecules, 20, 2241 (1987).

11. W. C. Yu, C. S. P. Sung, and R. E. Robertson, Macromolecules, 21, 355 (1988).

12. I. Mita, T. Naito, and K. Horie, J. Photopolym. Sci. Technol., 1, 303 (1988).

13. I. Mita, K. Horie, and K. Hirao, Macromolecules, 22, 558 (1989).

14. T. Naito, K. Horie, and I. Mita, Eur. Polym. J., 26, 1295 (1990).

15. T. Naito, K. Horie, and I. Mita, Macromolecules, 24(6) (1991), in press.

16. "Polyimides" M. I. Bessonov, M. M. Koton, V. V. Kudryavtsev, and L. A. Laius, Ed., Plenum Press, New York, N.Y., 1987.

17. T. Naito, K. Horie, and I. Mita, Polymer, in press.

18. T. Asano, T. Okada, S. Shinkai, K. Shigematsu, Y. Kusano, and O. Manabe, J. Am. Chem. Soc., 103, 5161 (1981).

19. A. F. Yee and S. A. Smith, Macromolecules, 14, 54 (1981).

20. K. Horie, M. Tsukamoto, and I. Mita, Eur. Polym. 
Effect of Polymer Rigidity on Photoisomerization

J., 21, 805 (1985).

21. M. Kochi, T. Sasaki, and H. Kambe, Polym. J., 10, 169 (1978).

22. M. Kochi and H. Kambe, Polym. Eng. Rev., 3, 355 (1983).

23. "Kobunshi Shinsozai Binran," Japanese Society of Polymer Science, Ed., Maruzen, 1990, p 87.
24. R. D. Deanin, "Polymer Structure, Properties and Applications," Cahners Books, 1972, p 201.

25. Hans-Georf Elias, translated by J. W. Stafford, "Macromolecules," Vol. 1, Plenum Press, New York, N.Y., 1977, p 164.

26. J. T. Edward, J. Chem. Educ., 47, 261 (1970). 